\title{
Effect Analysis of Unbalanced Electric Load in Ship at Three Phase Synchronous Generator on Laboratory Scale
}

\author{
Radhin D. Yulisetiawan, Eddy S. Koenhardono, and Sardono Sarwito \\ Marine Engineering Department, Marine Technology Faculty, Institut Teknologi Sepuluh Nopember (ITS) \\ Jl. Arief Rahman Hakim, Surabaya 60111 Indonesia \\ e-mail: eddy-koen@its.ac.id
}

\begin{abstract}
The generator is the main power supply of electricity in the ship. The generator can supply each ship's electricity consumer regarding the generator capacity and consumer requirement. Until now, some research been developed to increase the efficiency of the generator. Besides that, in the operation of generator, there are several problems that cause the generator works inefficient, which one is an unbalanced load on each phase in generator. This final project analyzed the effect of unbalanced load in three phase synchronous generator. In this research conducted a simulation of the operational of the generator on board ship with a laboratory experiment. This research includes the phasor diagram drawing, efficiency, as well as vibrations generated by the generator at several loading conditions. The research results were when the generator on $50 \%$ load of the generator capacity (240 Watt), and the loads are getting unbalanced, the power produced by the generator is increased $30 \%$, and the neutral current value also increased by $50 \%$, compared with balanced load condition. Besides that, the vibration value in each condition is tend to fluctuate. This is applied for another experiment. In accordance to the generator operation on ship is when the loads are getting unbalance, the fuel consumption also increase. This shows that there is dissipation use in fuel oil consumption
\end{abstract}

Keyword - Generator, Phasor Diagram, Power Produced, Unbalanced Load, Vibration

\section{INTRODUCTION}

Basically, the electrical system on board ship is similar to the electrical system on the land. The difference from the system only on the transmission system and the type of electric loads. Transmission of electrical power on board ship just a few hundred meters according to the length of the ship. While the transmission of electrical power on the land could reach tens to hundreds of kilometers according to the capacity of the power plant. Generator services on board include in pumps, compressors, and lighting. Electrical power supplies auxiliary machinery as a consumer. The demand of electrical power shall accommodate with sufficient amount. The impregnable supply is possible to construct with addition protection equipment for design and operation scope. Basically, the ship's electrical power system layout are essentially the same. [1]

An electric generator is a device that converts mechanical energy obtained from an external source into electrical energy as the output. Diesel Engine is one of the prime movers which drives an a.c generator to generate electrical energy. A diesel generating set system has some component, such as the diesel engine, the alternator, the switchgear and control system, the understructure and powerhouse, and the load arrangement. [2]

Synchronous generators especially have a slotted stator laminated core that has a three-, two-, or one-phase alternating current (AC) winding and excited by Permanent Magnet or DC current. [3]. The construction of generator has a two main parts, rotor, and stator. The synchronous generator for marine used is might be of the salient-pole type, and the field poles have a similar characteristic with d.c. generator. Sometimes, non-salient pole generators designed with distributed field windings embedded in slots may he used. The non-salient pole generators used in the high-speed engine, but with the improvement of technology, some builder selects them for all speeds. [4]

When the auxiliary engine is deteriorating, there are several condition that reduce the generator on board ship performance, such as fuel oil pressures too low, type of fuel burned, fuel leakage, fuel temperature, firing pressure difference, blocked filter, wrong valve clearance, damaged exhaust valve, high exhaust back pressure, contaminated passages, insufficient fresh air supply, high suction air temperature to $t / c$, charge air pressure is too low, wrong charge air temperature, charge air cooler contaminated, air cooler s.w temp high, air cooler s.w bypass open blower, turbine or nozzle ring worn/ damaged, scavenge air leakage, and wrong tappet clearance setting. [5]

Besides that, based on the type of electric load in the ship, mostly the type of electric load is three phase, while the rest is one phase. Although this one phase load is not much, it can affect the performance of the generator on board ship. This is because when the ship has a lot of one phase loads, it causes excessive load on the generator. And when one of the phases on generator has a difference number of current value, it means there has been unbalanced load in the generator.

The most important thing in balanced load is when the number of all three phasor voltage is equal to zero. This also applies when the number of phasor of currents in all threephase is also equal to zero. If the load impedance of the three phases does not have the same number, then the number of phasors and neutral current (In) is not equal to zero and the load is said to be unbalanced. In the case of trouble, the value of the neutral current in star/wye connection is not zero. Unbalanced load in the three-phase system can be determined by some indicators, such as the current in each phase is having a significant difference and abnormal current raising value in one phase. It can cause damage to the equipment. 
The current number in each phase continuously should have the same value. When the unbalanced load problem can be detected, the problem should be investigated and rearrange the circuit. A high number of single-phase load makes excessive heating in the stator and rotor of the generator. [6]

When three-phase synchronous generator in unbalanced load condition, the value of harmonic current is higher than balanced load condition, while the value of power factor in unbalanced condition is lower than balanced load condition. [7]. In transformator, the losses in balanced load are lower than unbalanced load condition. So, the efficiency of transformator in balanced load is higher than unbalanced load condition. [8]

In 1918, Fortesque found one theorem and the theorem called symmetrical component. He described how unbalanced three-phase voltages (or currents) could be transformed into 3 sets of balanced three-phase components. Until now, his invention called Fortesque theorem. Based on Fortesque theorem, there is three set of symmetrical component, namely:

a. Positive sequence (voltage/current)

Positive sequence means each phase has the same number and separated $120^{\circ}$, with the phase sequence as a clockwise rotation (A-B-C)

b. Negative sequence (voltage/current)

Negative sequence means each phase has the same number and separated $120^{\circ}$, with the phase sequence as a counterclockwise rotation (C-B-A)

c. Zero sequence (voltage/current)

Zero sequence means each phase has the same number but don't have phase angle. [9]

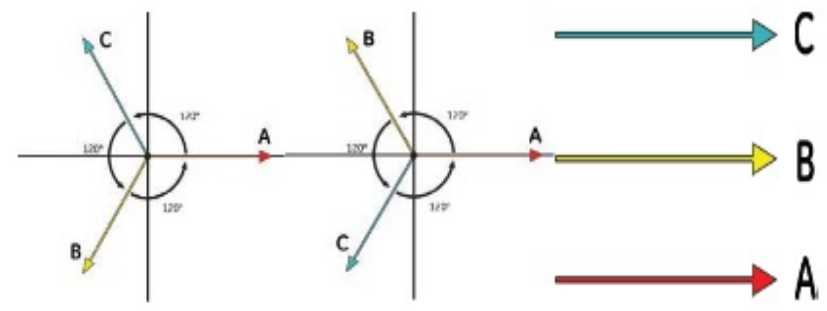

Figure 1 : Positive, Negative, and Zero Sequence

Source: An Introduction to Symmetrical Components, System Modelling, and Fault Calculation, 2013

Especially on board ship, where the type generator used is three phase diesel generator, several types of research focused to analyze the problem on the generator when the ship was sailing. Unbalanced load in the generator is one of the problems that often occur during the operation of the generator. Even on board ship, there is load share (equipment for automatically share the load equally) to solve this problem, this equipment can't be used for single generator operation.

Besides unbalanced load, vibration also has an effect on generator performance. There are several types of research about vibration in diesel generator on board ship to ensure that generator vibration can acceptable and follow the requirement which stated in the Classification Society Rules. Vibration is one of the easiest ways to detect the problem in the generator.
If the generator works with a high of vibration value, it can be ascertained that the generator doesn't work properly.

Vibration is one of the subjects that determined to sway in a mechanical system. It is characterized by amplitude and frequency. The movement of the structure, physical object or swaying force could be determined as vibration. Generally, the vibration in period could be expressed as sinusoidal or harmonic form. [10]

Generator vibration regularly checked by condition monitoring system to protect the generator itself. The effect of faults on generator vibration signatures, the effect of threephase fault (3PF), line-to-line fault (LLF), line-to-ground fault (LLGF) and line-to-ground fault (LGF) is obviously seen on $\mathrm{XY}$ plots and the time. LGF has the strongest magnitude gain followed by LLF. However, 3PF has the highest average gain. It means that although LGF and LLF could produce the strongest vibration magnitudes, a 3PF will most likely generate strong vibration responses. [11]. Generator vibration is one of the main factors which affects the design of the generator. To design the generator, the estimated value of generator acceleration and velocity should be known. [12]

Vibration analysis is one key to detecting the generator condition and preventing from some expected problem. There are some tools to analyze the generator vibration, such as vibration meter and accelerometer. If the generator works above the vibration standard limit, it means the generator has a bad performance. When the test already was done, compare the generator vibration with the international standard of electrical vibration standard. [13]

The International standard for vibration in motor or generator are IEC 34-14 and DIN EN 60034-14. Based on IEC, generator or motor vibration must be measured at rated voltage, rated frequency, with a virtually sinusoidal waveform, uncoupled from the prime mover and driven load. The three grades of balancing and respective maximum vibration level are listed in table 2.1

Table 2. 1 : Maximum allowable vibration acceleration based on IEC

\begin{tabular}{|c|c|c|c|c|c|}
\hline Grade & $\begin{array}{c}\text { Rated Speed } \\
(\mathrm{rm})\end{array}$ & \multicolumn{3}{|c|}{$\begin{array}{c}\text { Maximum rms. Values of Vibration Velocity (mm/s) } \\
\text { Machines Measured in a State of Free Suspension }\end{array}$} \\
\hline & & $56 \leq \mathrm{H}<132$ & $132(\mathrm{H} \leq 225$ & $225(\mathrm{H} \leq 400$ & $400<\mathrm{H} \leq 630$ \\
\hline $\mathrm{N}$ & $600 \leq \mathrm{n} \leq 1800$ & 1.8 & 1.8 & 2.8 & 2.8 \\
(normal) & $1800<\mathrm{n} \leq 3600$ & 1.8 & 2.8 & 4.5 & 4.5 \\
\hline $\mathrm{R}$ & $600 \leq \mathrm{n} \leq 1800$ & 0.71 & 1.12 & 1.8 & \\
(reduced) & $1800<\mathrm{n} \leq 3600$ & 1.12 & 1.8 & 2.8 & \\
\hline $\mathrm{S}$ & $600 \leq \mathrm{n} \leq 1800$ & 0.48 & 0.71 & 1.12 & \\
(special) & $1800<\mathrm{n} \leq 3600$ & 0.71 & 1.12 & 1.8 & \\
\hline
\end{tabular}

Source: IEC Standard

Besides IEC, there is an international vibration standard, DIN EN 600034-14. The difference between IEC standard and DIN standard only in vibration frequency allowable. 
Table 2. 2 : Maximum allowable vibration acceleration based on DIN

\begin{tabular}{|c|c|c|c|c|}
\hline \multirow{2}{*}{ Grade } & \multirow{2}{*}{$\begin{array}{c}\text { Rated } \\
\text { Speed } \\
(\mathrm{rpm})\end{array}$} & \multicolumn{3}{|c|}{$\begin{array}{c}\text { Limits of Vibration Velocity } \\
(\mathrm{mm} / \mathrm{s}) \text { in Frequency Range 10 } \\
\text { up to 1000 Hz sizes }\end{array}$} \\
\cline { 3 - 5 } & & $80-112$ & $132-200$ & $225-400$ \\
\hline $\mathrm{N}$ & $600-3600$ & 1.8 & 2.8 & 3.5 \\
\hline \multirow{2}{*}{$\mathrm{R}$} & $600-1800$ & 0.71 & 1.12 & 1.8 \\
& $1800-3600$ & 1.12 & 1.8 & 2.8 \\
\hline \multirow{2}{*}{$\mathrm{S}$} & $600-1800$ & 0.45 & 0.71 & 1.12 \\
& $1800-3600$ & 0.71 & 1.12 & 1.8 \\
\hline
\end{tabular}

Source: DIN Standard

Until now, there is no research that combines the effect of unbalanced load and vibration in the generator. On the previous research just focused on unbalanced load in a generator with some variations, neither does the vibration. Even though, unbalanced load and vibration are one of a problem on generator works which has an effect on generator efficiency.

Basically, the efficiency of all electricity equipment is output divided by input. Especially in the generator, the input power taken from the motor which drives the generator. It can be diesel, electric, or steam. Each motor has different efficiency. After input power, there is output power. The output power value is taken from the load which covered by the generator. After the input and output power value were known, compare the value. The efficiency of generator usually presented in percentage.

a. Balanced Condition

A balanced three-phase load is one that is equally shared (balanced) across all three phases. The total load is determined by adding up the individual $\mathrm{kW}$ balanced loads. In the balanced systems, the average power consumed by each load branch is the same and given by

$$
\widetilde{P}_{a v}=V_{\text {eff }} I_{\text {eff }} \cos \phi
$$

where $V_{\text {eff }}$ is the effective value of the phase voltage, $I_{\text {eff }}$ is the effective value of the phase current and $\phi$ is the angle of the impedance. The total average power consumed by the load is the sum of those consumed by each branch, hence, we have

$$
P_{a v}=3 \widetilde{P}_{a v}=3 V_{\text {eff }} I_{\text {eff }} \cos \phi
$$

In the balanced Y-systems, the phase current has the same amplitude as the line current $\mathrm{I}_{\text {eff }}=\left(\mathrm{I}_{\mathrm{eff}}\right)_{\mathrm{L}}$, whereas the line voltage has the effective value $(\mathrm{V} \text { eff })_{\mathrm{L}}$ which is $\sqrt{3}$ times greater than the effective value of the phase voltage, $\left(\mathrm{V}_{\text {eff }}\right)_{\mathrm{L}}=$ $\sqrt{3} \mathrm{~V}$ eff. Hence, using equation (2), we obtain

$P_{a v}=3 \frac{\left(V_{\text {eff }}\right)_{L}}{\sqrt{3}}\left(I_{\text {eff }}\right)_{L} \cos \phi=\sqrt{3}\left(V_{\text {eff }}\right)_{L}\left(I_{\text {eff }}\right)_{L} \cos \phi$

b. Unbalanced Condition

An unbalanced 3 phase load is one in which the load is not equally distributed over all the three phases. To obtain the equivalent 3 phase rating the highest single phase loading must be multiplied by 3 . An unbalanced load gives rise to unequal phase to phase and phase to neutral voltages. In the unbalanced systems, there are adding the powers of each phase

$P_{a v}=\left(V_{e f f}\right)_{a}\left(I_{e f f}\right)_{a} \cos \phi_{a}+\left(V_{e f f}\right)_{b}\left(I_{e f f}\right)_{b} \cos \phi_{b}+\left(V_{e f f_{c}}\right)_{e f f_{c}} \cos \phi_{c}$
Therefore, there should be further analysis of the generator performance, which the performance data can be obtained from some parameter, such as vibration and load condition (balance and unbalance). And then it can be seen what is the effect of vibration and load condition in generator efficiency. Later, this research can be a used as a recommendation to use the generator as efficiently as possible.

Based on the literature review, there is some hypothesis formulated as follows:

1. The effect of unbalanced load on three phase synchronous generator is the phasor diagram, not separate $120^{\circ}$, and the neutral current will be increased.

2. The generator efficiency value in balanced load is higher than unbalanced load condition.

3. The generator vibration value in balanced load is lower than unbalanced load condition.

\section{RESEARCH METHOD}

\section{A. General}

This final project analyzed the effect of unbalanced load in three phase synchronous generator. In this research conducted a simulation of the operational of the generator on board ship with a laboratory experiment. This research analyzed includes the phasor diagram drawing, efficiency, as well as vibrations generated by the generator at several loading conditions

\section{B. Generator Specification}

The generator which used is located at Marine Electrical and Automation System (MEAS) Laboratory, Marine Engineering Department Program. This is the technical data from generator and motor which used in the laboratory:

$$
\begin{array}{ll}
\text { 1. } & \text { DC Motor Power }=1,5 \mathrm{KW} \\
\text { 2. } & \text { AC Motor Power }=1,5 \mathrm{KW}(\operatorname{Cos} \theta=0,8) \\
\text { 3. } & \text { Generator Power }=600 \mathrm{VA}(480 \mathrm{Watt})
\end{array}
$$

\section{Laboratory Experiment Procedure}

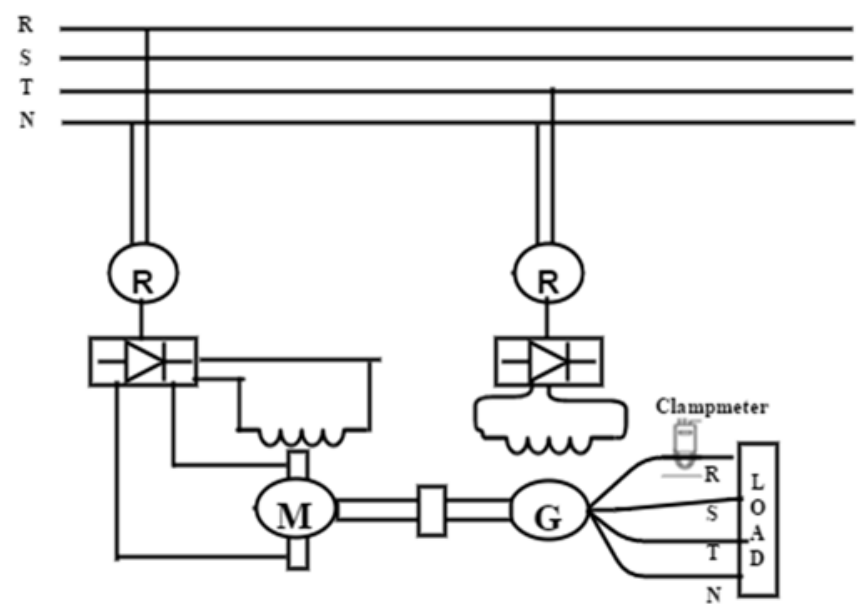

Figure 2. Laboratory Experiment Procedure There is equipment and procedure describes as follows:

a. Incandescent Light Bulb Lamp 40 Watt 
b. Electrical Source (In this case is three phase synchronous generator) in MEAS Laboratory

c. Vibration meter

d. Hioki 3280 Clamp

e. Another Equipment

The experiment stages describe as follows:

a. Turn on the switch on/off in AC Motor

b. If the generator driven by DC motor, rotate the regulator to drive the DC motor

c. Measure the value of excitation current from regulator

d. Take the RO Phase value 220 Volt

e. Measure the value of phase voltage

f. Measure the value of each phase current

g. Measure the value of acceleration and velocity value to obtain vibration value

h. Measure the rpm of generator

After the data was recorded, then use the same steps on variation of generator load (From 25\% - 100\%) with balanced and unbalanced load condition in each generator load.

\section{DATA ANALYSIS}

\section{A. Phasor Diagram (Comparison on Load 240 Watt)}

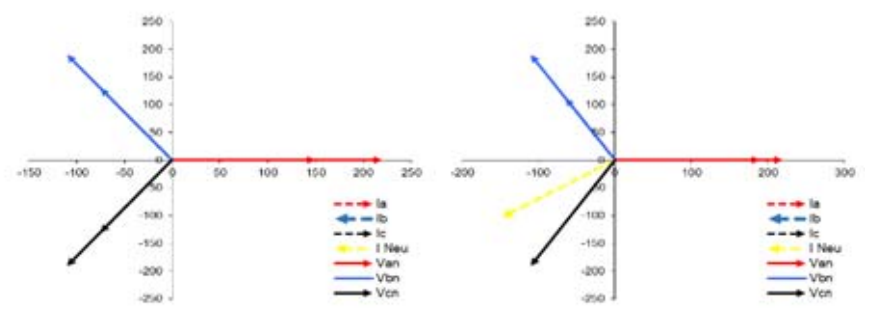

Figure 3. Phasor Diagram Generator Driven by DC Motor Load 240 Watt

1) Generator driven by DC Motor Load 240 Watt

Figure 4 describes the different of balanced and unbalanced load condition phasor diagram on a generator driven by de motor. On balanced condition (left figure), there is no neutral current value and each phase separate $120^{\circ}$. In unbalanced condition (right figure), there is neutral current value and each phase don't separate $120^{\circ}$.

\section{2) Generator driven by AC Motor Load 240 Watt (VoltagRO} Drop)

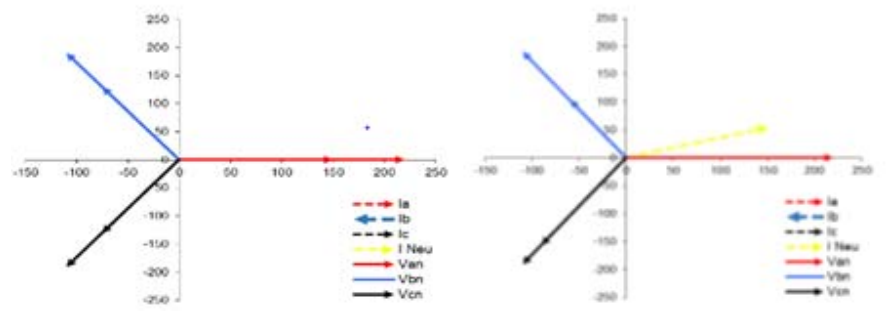

Figure 4. Phasor Diagram Generator Driven by AC Motor Load 240 Watt (Voltage RO Drop)
Figure 5 describes the different of balanced and unbalanced load condition phasor diagram on a generator driven by ac motor (Voltage RO Drop). On balanced condition (left figure), there is no neutral current value and each phase separate $120^{\circ}$. Unbalanced condition (right figure), there is neutral current value and each phase don't separate $120^{\circ}$.

\section{3) Generator driven by AC Motor Load 240 Watt}

Figure 3 describes the different of balanced and unbalanced load condition phasor diagram on a generator driven by ac motor (Voltage RO 220). On balanced condition (left figure), there is no neutral current value and each phase separate $120^{\circ}$. Unbalanced condition (right figure), there is neutral current value and each phase don't separate $120^{\circ}$.

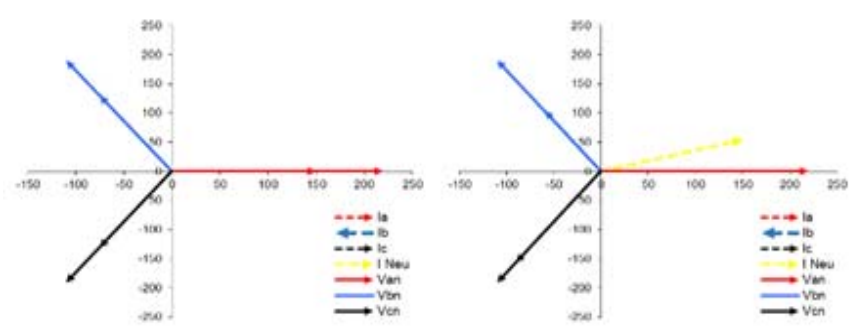

Figure 5. Phasor Diagram Generator Driven by AC Motor Load 240 Watt (Voltage RO 220)

B. Generator Power Produced

1) Generator driven by DC Motor

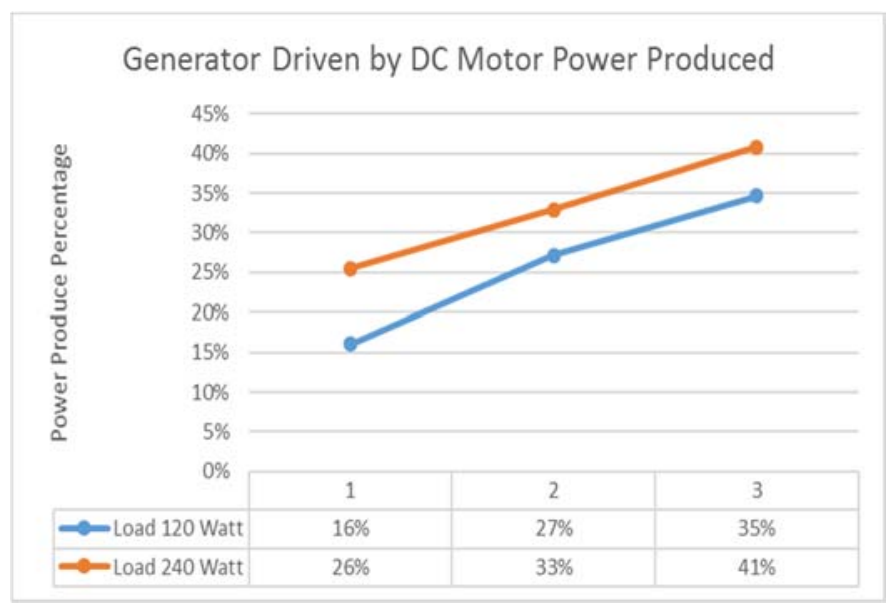

Graph 1 : Generator driven by DC Motor Power Produced Comparison

Graph 1 describes the comparison value between balanced and unbalanced condition in each load on generator driven by $\mathrm{dc}$ motor. When the loads condition getting unbalanced (from left to right), the value of power produced by the generator increases. It means, by the same number of loads, generator produced more power. So, there is inefficient energy used when generator works in unbalanced condition. 


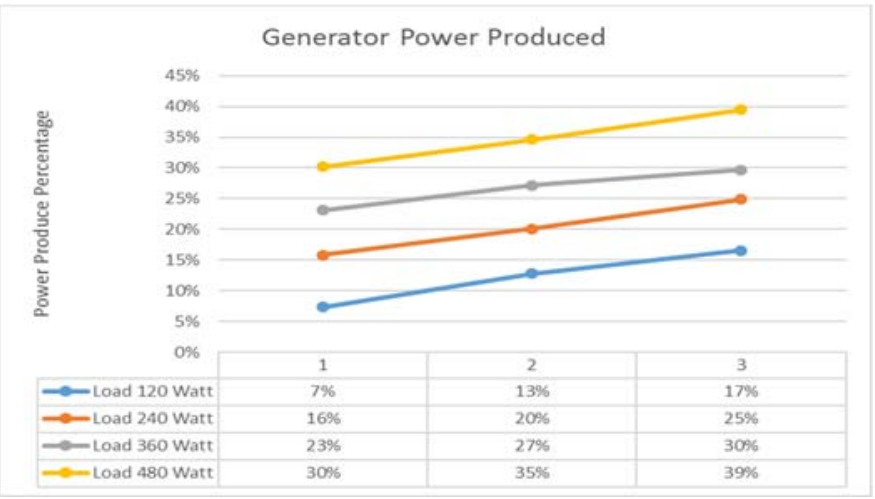

Graph 2 : Generator driven by AC Motor Load (Voltage RO Drop) Power Produced Comparison

2) Generator driven by AC Motor (Voltage RO Drop)

Graph 2 describes the comparison value between balanced and unbalanced condition in each load on generator driven by ac motor (Voltage RO Drop). When the loads condition getting unbalanced (from left to right), the value of power produced by the generator increases. It means, by the same number of loads, generator produced more power. So, there is inefficient energy used when generator works in unbalanced condition.

3) Generator driven by AC Motor Load 240 Watt (Voltage RO 220)

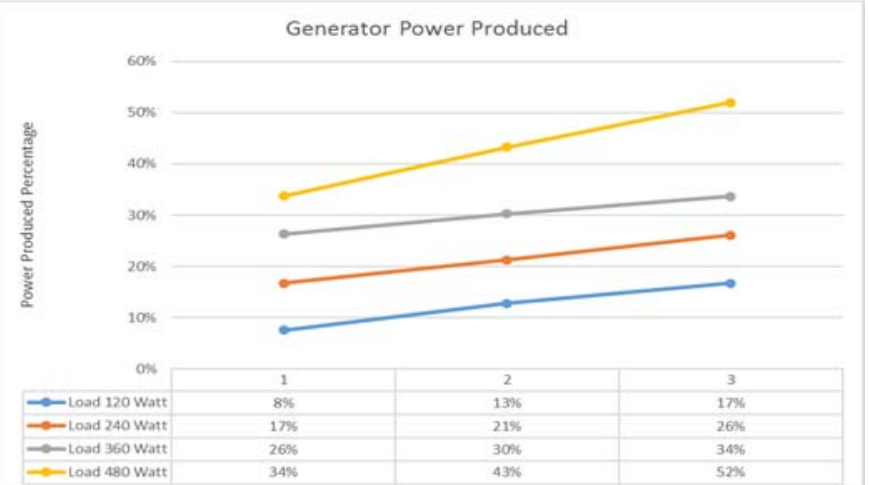

Graph 3 : Generator driven by AC Motor Load 240 Watt (Voltage RO 220) Power Produced Comparison

Graph 3 describes the comparison value between balanced and unbalanced condition in each load on generator driven by ac motor (Voltage RO 220). When the loads condition getting unbalanced (from left to right), the value of power produced by the generator increases. It means, by the same number of loads, generator produced more power. So, there is inefficient energy used when generator works in unbalanced condition.

\section{Vibration (Comparison on Load 240 Watt)}

A graph of these vibrations used to analyze if these results in accordance with this research hypothesis early and standard used. Basically, the vibration result can't prove this research hypothesis that the generator vibration value in balanced load is lower than unbalanced load condition. This is because the generator which used in this experiment has a low power. Besides that, the age also affects the generator performance. The generator is too old and works in poor performance.

\section{1) Generator driven by DC Motor}

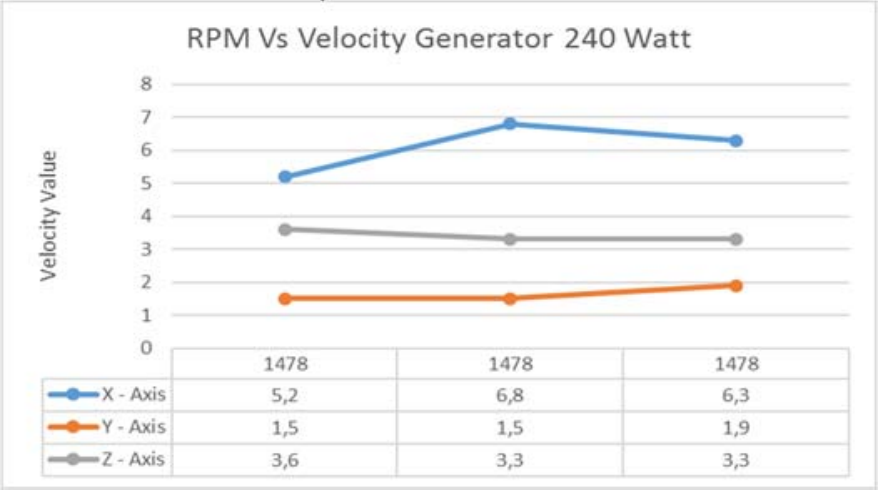

Graph 4 : RPM Vs Velocity Generator driven by DC Motor

Graph 4 describes the comparison value between balanced and unbalanced condition on generator driven by dc motor on load 240 watts. It can be seen that when the loads condition getting unbalanced (from left to right) the velocity value in each axis $(\mathrm{X}, \mathrm{Y}, \mathrm{Z})$ are ridden down (fluctuate). So, there is no difference vibration between balanced and unbalanced load condition.

2) Generator driven by AC Motor (Voltage RO Drop)

Graph 6 describes the comparison value between balanced and unbalanced condition on generator driven by ac motor (Voltage RO Drop) on load 240 watt. It can be seen that when the loads condition getting unbalanced (from left to right) the velocity value in each axis $(\mathrm{X}, \mathrm{Y}, \mathrm{Z})$ are ridden down (fluctuate). So, there is no difference vibration between balanced and unbalanced load condition.

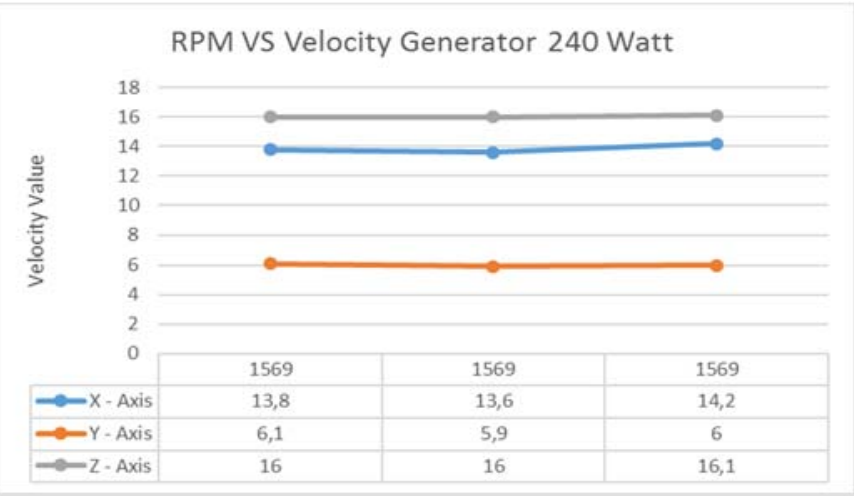

Graph 5 : RPM Vs Velocity Generator driven by AC Motor (Voltage RO Drop)

3) Generator driven by AC Motor (Voltage RO 220)

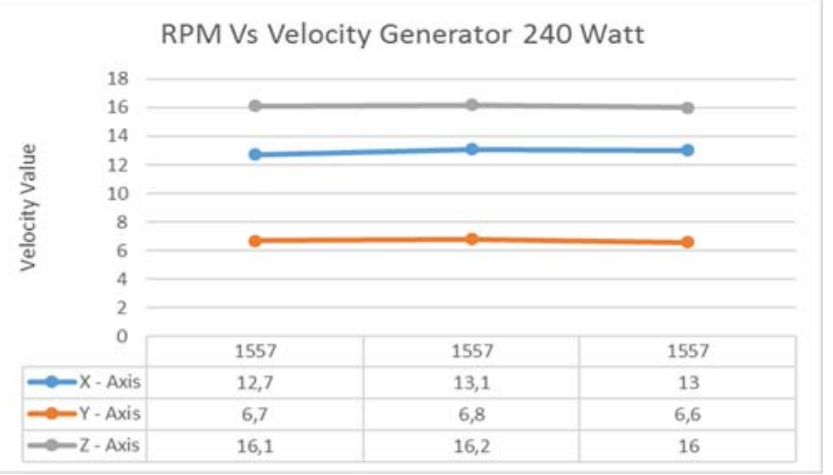

Graph 6 : RPM Vs Velocity Generator driven by AC Motor (Voltage RO 220 ) 
Graph 7 describes the comparison value between balanced and unbalanced condition on generator driven by ac motor (Voltage RO 220) on load 240 watt. It can be seen that when the loads condition getting unbalanced (from left to right) the velocity value in each axis $(\mathrm{X}, \mathrm{Y}, \mathrm{Z})$ are ridden down (fluctuate). So, there is no difference vibration between balanced and unbalanced load condition.

\section{Generator Neutral Current Comparison}

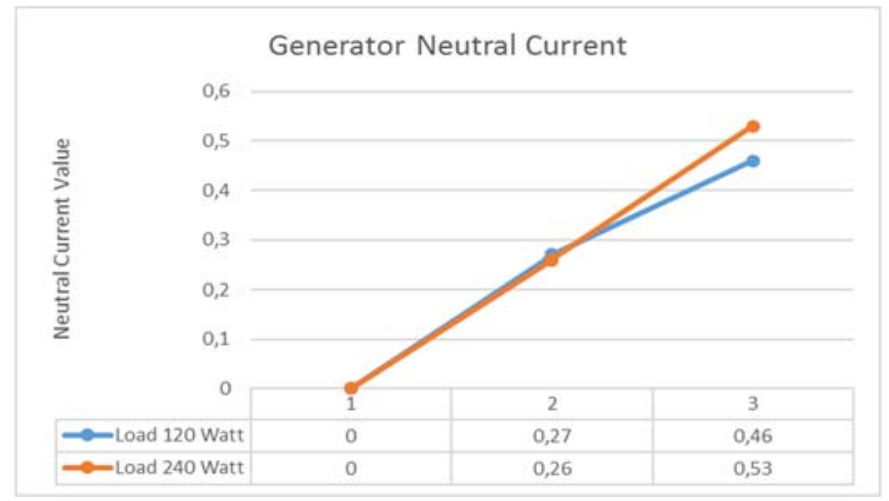

Graph 7 : Generator driven by DC Motor Neutral Current Value

\section{1) Generator driven by DC Motor}

Graph 5 describes the neutral current value on generator driven by dc motor. When the loads condition getting unbalanced (from left to right), the value of the generator neutral current increases. It can damage electrical consumer which supplied by the generator.

\section{2) Generator driven by AC Motor (Voltage RO Drop)}

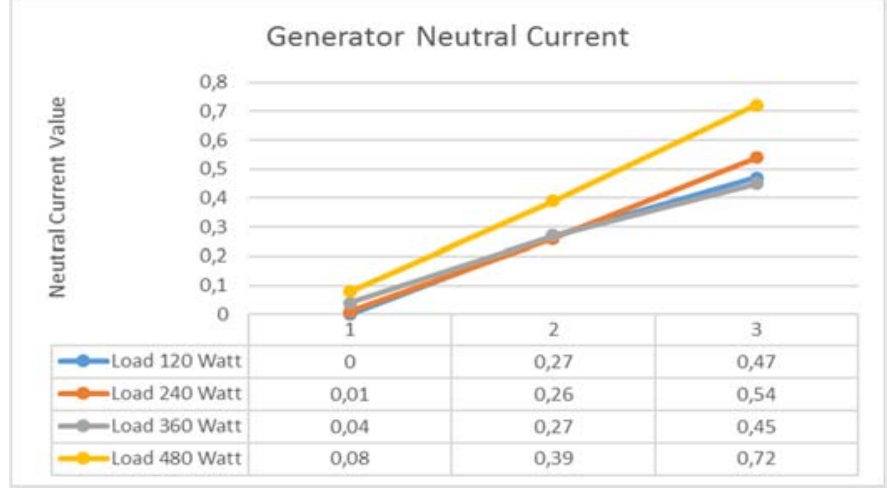

Graph 8 : Generator driven by AC Motor (Voltage RO 220)

Graph 8 describes the neutral current value on generator driven by ac motor (Voltage RO 220). When the loads condition getting unbalanced (from left to right), the value of the generator neutral current increases. It can damage electrical consumer which supplied by the generator.

3) Gerator driven by AC Motor (Voltage RO 220)

Graph 9 describes the neutral current value on generator driven by ac motor (Voltage RO 220). When the loads condition getting unbalanced (from left to right), the value of the generator neutral current increases. It can damage electrical consumer which supplied by the generator.

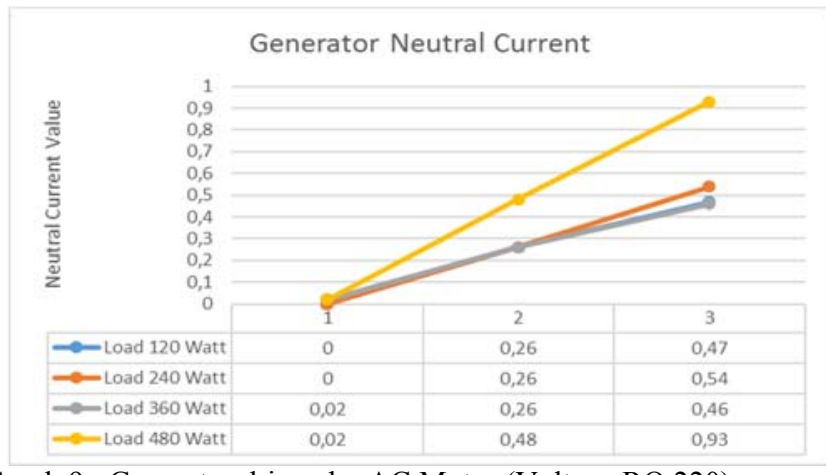

Graph 9 : Generator driven by AC Motor (Voltage RO 220)

\section{CONCLUSION AND RECOMMENDATION}

Based on the laboratory experiment and data analysis, it can be concluded that if the generator on $50 \%$ load of the generator capacity (240 Watt), and the loads are getting unbalanced, the neutral current value also increased by $50 \%$, compared with balanced load condition.

Then, if the value of unbalance load is increased, the phasor diagram not separate $120^{\circ}$. besides that, if the generator on $50 \%$ load of the generator capacity (240 Watt), and the loads are getting unbalanced, the power produced by the generator is increased $30 \%$, compared with balanced load condition.

In balanced and unbalanced load condition, the value of generator vibration is tend to fluctuate. If the load of the generator increased, the generator vibration value increased by $20 \%$ in each balanced and unbalanced condition. The vibration value which generated by the generator driven by an ac motor is higher $50 \%$ than generator driven by dc motor (in the same number of load). Based on IEC 34-14 and DIN EN 60034-14 standard in generator rpm $600<\mathrm{n}<1800$, the generator velocity which acceptance is $1,8 \mathrm{~mm} / \mathrm{s}$. while the generator velocity in 120 Watt load, the highest velocity is $6,8 \mathrm{~m} / \mathrm{s}$ (DC motor) and aa, $6 \mathrm{~m} / \mathrm{s}$ (AC motor). It means that the generator vibration has not met the qualification of the standard.

The recommendation from this research are there is further research on experiment with higher generator power and load. Besides that, next time the research analyzed the unbalanced load with the data taken from auxiliary engine onboard ship, and add an problem to analyze the effect of neutral current increased

\section{REFERENCES}

[1] Dennis T. Hall B.A. (Honsl, G. E. (1999). Praktical Marine Electrical Knowledge (Second Edition). London: Witherby \& Co Ltd.

[2] Efficiency, B. o. (2005, January). Diesel Generating Set System. Retrieved from Bureau of Energy Efficiency Website: https://www.beestarlabel.com/

[3] Ion Boldea, Syed Nasar. (2006). Synchronous Generator Handbook. Florida: CRC Press Taylor and Francis Group.

[4] Watson, G. (1991). Marine Electrical Practice. England: ButterworthHeinemann.

[5] Anish. (2015, December 28). 20 Possible Causes for Reduction in Ship's Auxiliary Engine Performance. Retrieved from Marine Insight: http://www.marineinsight.com/tech/generator/ships-auxiliary-engineperformance/

[6] Watson, G. (1991). Marine Electrical Practice. England: ButterworthHeinemann. 
[7] Cumentas, Ismail; Waluyo; Nasrun Hariyanto. (2013). Analisis Pengaruh Ketidakseimbangan Kondisi Beban terhadap Harmonik Arus dan Faktor Daya Generator Sinkron Tiga Fasa. Reka Elkomika, I(3), 258 -259 .

[8] Lumbanraja, H. (2008). Pengaruh Beban TIdak Seimbang Terhadap Efisiensi Transformator Tiga Fasa Hubungan Open Delta. Medan: USU Respository.

[9] Marx, Stephen ; Bender, Dean;. (2013). An Introduction to Symmetrical Components, System Modelling, and Fault Calculation. HANDS-ON Relay School, (pp. 3-9). Washington.

[10] Harris, C., \& Piersol, A. (2002). Harris' Shock and Vibration Handbook. New York: McGraw Hill.

[11] Jr, Rolando Oliquino; S. Islam; H. Eren. (2010). Effects of Types of Faults on Generator Vibration Signatures. Generator Vibration Signatures, 1.

[12] Irasari, Pudji; Aditya Sukma Nugraha; Muhamad Kasim. (2010). Analisis Getaran Pada Generator Magnet Permanent $1 \mathrm{KW}$ Hasil Rancang Bangun Pusat Penelitian Tenaga Listrik dan Mekatronik. Journal of Mechatronics, Electrical Power, and Vehicular Technology, $2-4$.

[13] Sohler, A. S. (1999). Electric Motor Vibration. 1. 